\title{
Efficacy and safety of hylan G-F 20 injection in treatment of knee osteoarthritis in Chinese patients: results of a prospective, multicentre, longitudinal study
}

\author{
CH Yan *, WL Chan, WH Yuen, Patrick SH Yung, KY Ip, Jason CH Fan, KY Chiu
}

\section{A B S T R A C T}

Objective: To study the efficacy and safety of single intra-articular injection of $6-\mathrm{mL}$ hylan G-F 20 in Chinese patients with symptomatic knee osteoarthritis.

Design: Prospective case series.

Setting: Six government hospitals in Hong Kong.

Patients: Patients with primary knee osteoarthritis were recruited from six government hospitals from 1 October 2010 to 31 May 2012. All patients received 6-mL intra-articular injection of hylan G-F 20.

Main outcome measures: Pain visual analogue scale, functional visual analogue scale, and 5-point Likert scale on change of pain and function were assessed. Adverse events were checked. Radiographs were taken pre-injection and at 3 months and 1 year.

Results: A total of 110 knees of 95 patients with primary knee osteoarthritis were treated. The mean age of the patients was 62 (standard deviation, 9.8) years. All patients completed 1 year of follow-up. The mean pain visual analogue scale, functional visual analogue scale, and Likert value for pain and function showed statistically significant improvements at 6 weeks, 3 months, 6 months, and 1 year compared with the pre-injection values. No significant correlations were found between changes

This article was published on 19 Jun 2015 at www.hkmj.org. in visual analogue scale and age, body mass index, pre-injection radiological osteoarthritis severity, serum erythrocyte sedimentation rate, or C-reactive

protein. Serial radiographs did not show any changes in the radiological severity of knee osteoarthritis. Overall, $16.4 \%$ of the patients experienced mild and self-limiting adverse events.

Conclusion: Hylan G-F 20 is a safe and effective therapy to relieve pain and improve function for up to 1 year in Chinese patients with knee osteoarthritis.

\section{Hong Kong Med J 2015;21:327-32}

DOI: 10.12809/hkmj144329

CH Yan *, FHKCOS, FHKAM (Orthopaedic Surgery)

${ }^{2}$ WL Chan, FHKCOS, FHKAM (Orthopaedic Surgery)

${ }^{3}$ WH Yuen, FHKCOS, FHKAM (Orthopaedic Surgery)

${ }^{4}$ PSH Yung, FHKCOS, FHKAM (Orthopaedic Surgery)

${ }^{5} \mathrm{KY}$ Ip, FHKCOS, FHKAM (Orthopaedic Surgery)

${ }^{6} \mathrm{JCH}$ Fan, FHKCOS, FHKAM (Orthopaedic Surgery)

${ }^{1}$ KY Chiu, FHKCOS, FHKAM (Orthopaedic Surgery)

Department of Orthopaedics and Traumatology, The University of Hong Kong, Queen Mary Hospital, Pokfulam, Hong Kong

2 Department of Orthopaedics and Traumatology, Kwong Wah Hospital, Yaumatei, Hong Kong

Department of Orthopaedics and Traumatology, Queen Elizabeth Hospital, Jordan, Hong Kong

${ }^{4}$ Department of Orthopaedics and Traumatology, The Chinese University of Hong Kong, Prince of Wales Hospital, Shatin, Hong Kong

${ }^{5}$ Department of Orthopaedics and Traumatology, North District Hospital, Sheung Shui, Hong Kong

Department of Orthopaedics and Traumatology, Alice Ho Miu Ling Nethersole Hospital, Tai Po, Hong Kong

* Corresponding author: yanchunhoi@gmail.com

New knowledge added by this stud

- This study demonstrated that hylan G-F 20 is effective and safe to treat knee osteoarthritis in Chinese patients. Past studies were only conducted in Caucasian or mixed populations.

Implications for clinical practice or policy

- Viscosupplementation could be a valid option for managing patients with chronic and symptomatic knee osteoarthritis. Single injection preparation is safe and effective. Injection can be performed in an out-patient setting.

\section{Introduction}

Osteoarthritis $(\mathrm{OA})$ is a progressive degenerative joint disease initiated by multiple aetiological factors. When clinically evident, $\mathrm{OA}$ is characterised by joint pain, tenderness, stiffness, crepitus, effusion, and variable degrees of inflammation without systemic effects. Knee OA is a leading musculoskeletal cause of disability in elderly people around the world, and affects both Caucasian and Chinese populations. ${ }^{1-3}$ The burden of disease dramatically impacts health care costs. A local study found that, excluding joint replacement, the direct costs of 


\section{注射hylan G-F 20治療華籍患者膝關節骨性關節 炎的功效和安全性：前瞻性、縱向多中心研究} 忻振凱、陳偉霖、袁偉康、容樹恆、葉啟源、范智豪、曲廣運 目的：研究替膝關節骨性關節炎華籍患者在關節內注射6毫升hylan G-F 20的功效和安全性。

設計：前瞻性病例系列研究。

安排：香港六間公立醫院。

患者：於2010年10月 1 日至2012年5月31日期間曾到六間公立醫院的 原發性膝關節骨性關節炎患者均被列入研究範圍。所有患者接受在關 節內注射6毫升hylan G-F 20。

主要結果測量：疼痛視覺模擬評分、功能性視覺模擬評分, 以及 5 點 李克特量表上的疼痛和功能變化; 是否有不良事件, 以及於注射前 注射後三個月和一年替患者進行的X光檢查。

結果：研究對象為95名（110例）原發性膝關節骨性關節炎患者, 他 們平均年齡62歲（標準差9.8歲）。所有患者均完成一年隨訪。與注 射前比較, 患者在注射後第六週、三個月、六個月和一年的疼痛視覺 模擬評分、功能性視覺模擬評分和 5 點李克特量表的平均分在統計學 上均有顯著改善。視覺模擬評分的改變與以下各項沒有顯著相關性： 患者年齡、身體質量指數、注射前放射性骨關節炎的嚴重程度、血紅 細胞沉降率或C反應蛋白。連續的放射照片亦沒有顯示膝關節骨性關 節炎重度有任何變化。16.4\%患者出現輕微和自限性不良事件。

結論：替膝關節骨性關節炎華籍患者注射hylan G-F 20能安全而有效 地減輕疼痛和改善膝關節功能, 療效可維持長達一年。 managing OA ranged from HK\$11690 to $\$ 40180$ per person per year and indirect costs ranged from HK\$3300 to $\$ 6640.4$

There are many types of treatment for knee OA. These therapies can be divided into two major groups of non-surgical and surgical. Non-surgical therapies include exercise, weight loss, physical therapy, occupational therapy, medications (eg paracetamol, non-steroidal anti-inflammatory agents), and intra-articular injections (steroids, viscosupplementation). Surgical therapies mainly entail osteotomy and arthroplasty. ${ }^{5}$

Knee OA has been associated with a decrease in the elasticity and viscosity of the synovial fluid, ${ }^{6-8}$ which may alter the transmission of mechanical forces to the articular cartilage, possibly increasing its susceptibility to mechanical damage, or wear and tear. Viscosupplementation is an intra-articular therapeutic modality based on the physiological importance of hyaluronan in synovial joints. Its therapeutic goal is to restore the viscoelasticity of synovial hyaluronan, decrease pain, improve mobility, and restore the natural protective functions of hyaluronan in the joint.
Hylan G-F 20 is a cross-linked sodium hyaluronate with a high average molecular weight of 6 million daltons. Hylan G-F 20 is used in North America and Europe for the treatment of pain associated with knee OA. However, there are no data available in the literature on the clinical benefits of the viscosupplement in Chinese populations. Therefore, we carried out a prospective, multicentre, longitudinal study to investigate the efficacy and safety of hylan G-F 20 in the treatment of knee OA in local Chinese patients over a period of 1 year.

\section{Methods}

The study protocol was approved by the Institutional Review Boards/Ethics Committees of all six participating centres in Hong Kong. The inclusion criteria were: Chinese patients with primary knee OA who fulfilled the diagnostic criteria of the American College of Rheumatology; knee pain visual analogue scale (VAS) score of $>50$ (range, $0-100)$ and/or functional VAS score of $>50$ (0-100); and willingness to pay for the viscosupplementation and participate in the study. The exclusion criteria were: knee arthritis of other aetiologies; knee surgery or previous intra-articular injection in the knee within 1 year of the study; known allergy to chicken extracts; or unwillingness to pay for the viscosupplementation or participate in the study. Weight-bearing radiographs of the affected knee joint (standard anteroposterior and lateral views) were taken at the screening visit. Severity of knee OA in the tibiofemoral and patellofemoral compartments was classified according to the Kellgren-Lawrence (KL) system. The overall severity was defined as the highest KL grade in any of the compartments. We also documented the patients' body mass index (BMI), and checked serum erythrocyte sedimentation rate (ESR) and C-reactive protein (CRP) level.

Single intra-articular preparation of $6 \mathrm{~mL}$ of hylan G-F was injected into the patients' knees in the out-patient clinic. Strict aseptic technique was adopted with skin disinfection and draping. The injection was administered through a direct lateral parapatellar approach. Knee joint aspiration was performed using a separate syringe before injection of the viscosupplement. After injection, the patients were allowed to resume normal activities, but were advised against vigorous exercise for 2 to 3 days. Ice therapy was recommended in case of transient increase in pain and swelling. Patients could continue with their routine analgesics on a pro re nata basis.

All patients were followed up regularly at 6 weeks, 3 months, 6 months, and 1 year. A telephone interview was conducted at 2 weeks to record any adverse events, if present. The severity of knee pain and knee function using 0-100 VAS scores (where 0 represents 'no pain' or 'normal function') were documented at each visit. Any changes in knee 
pain and functional limitations were charted using a 5-point Likert scale. Standard radiographs of the knee were repeated at 3 months and 1 year to detect any changes in radiological severity.

The change in pain and functional VAS scores before and after injection during each visit was compared using paired $t$ test. Using correlation tests, we tried to find out the predictive factors (including age, sex, BMI, pre-injection KL grade, pre-injection pain VAS, ESR, and CRP) of favourable treatment response. All analyses were performed using the Statistical Package for the Social Sciences (Windows version 20.0; SPSS Inc, Chicago [IL], US). Statistical significance was assumed if the $\mathrm{P}$ value was $<0.05$.

\section{Results}

A total of 110 knees of 95 patients (31 men and 64 women) were recruited from six government hospitals in Hong Kong from 1 October 2010 to 31 May 2012. There were 59 left knees and 51 right knees. All patients completed 1 year of follow-up. The mean ( \pm standard deviation) age of the patients was $62.0 \pm 9.8$ (range, 33-86) years. The mean BMI was $27.7 \pm 4.6 \mathrm{~kg} / \mathrm{m}^{2}$ (range, $18.3-46.8 \mathrm{~kg} / \mathrm{m}^{2}$ ). The mean ESR was $23.35 \pm 14.00 \mathrm{~mm} / \mathrm{h}$ (range, 2.00$66.00 \mathrm{~mm} / \mathrm{h}$ ) and the mean CRP level was $1.3 \pm 1.7$ $\mathrm{mg} / \mathrm{L}$ (range, 0.1-7.1 $\mathrm{mg} / \mathrm{L}$ ). The youngest patient in the study was 33 years old. His BMI was $25.9 \mathrm{~kg} / \mathrm{m}^{2}$. $\mathrm{X}$-rays of his right knee showed KL grade $1 \mathrm{OA}$ in the patellofemoral compartment and KL grade $2 \mathrm{OA}$ in the tibiofemoral compartment. He denied any previous injury to his knee.

The mean pain and functional VAS scores are shown in Figures 1 and 2, respectively. There were statistically significant improvements in pain and functional VAS scores after injection at every followup visit when compared with the pre-injection scores (paired $t$ test, $\mathrm{P}<0.0001$ for all). Significant differences were also found between the pain and functional VAS scores at 1 year and at 6 weeks $(\mathrm{P}<0.001$ and $\mathrm{P}<0.01$, respectively), 3 months $(\mathrm{P}<0.003$ and $\mathrm{P}<0.01$, respectively), and 6 months ( $\mathrm{P}<0.01$ for both). The score differences between 6 weeks, 3 months, and 6 months were not significant.

Likert values were coded as 1 to 5 with 3 being no change and 1 being much reduced. A sign test against a median of 3 and an alternate hypothesis that the sample median was less than 3 was used. Significant reductions in pain and functional limitations were found at 6 weeks $(\mathrm{P}<0.001$ for both), 3 months $(\mathrm{P}<0.001$ for both), 6 months $(\mathrm{P}<0.001$ for both), and 1 year $(\mathrm{P}<0.03$ for both). The proportion of patients feeling reduced or much reduced pain was $74 \%$ at 6 weeks, $75 \%$ at 3 months, $62 \%$ at 6 months, and $49 \%$ at 1 year. The proportion of patients feeling no change in pain level (when compared with preinjection level) was $23 \%$ at 6 weeks, $22 \%$ at 3 months, $33 \%$ at 6 months, and $43 \%$ at 1 year.

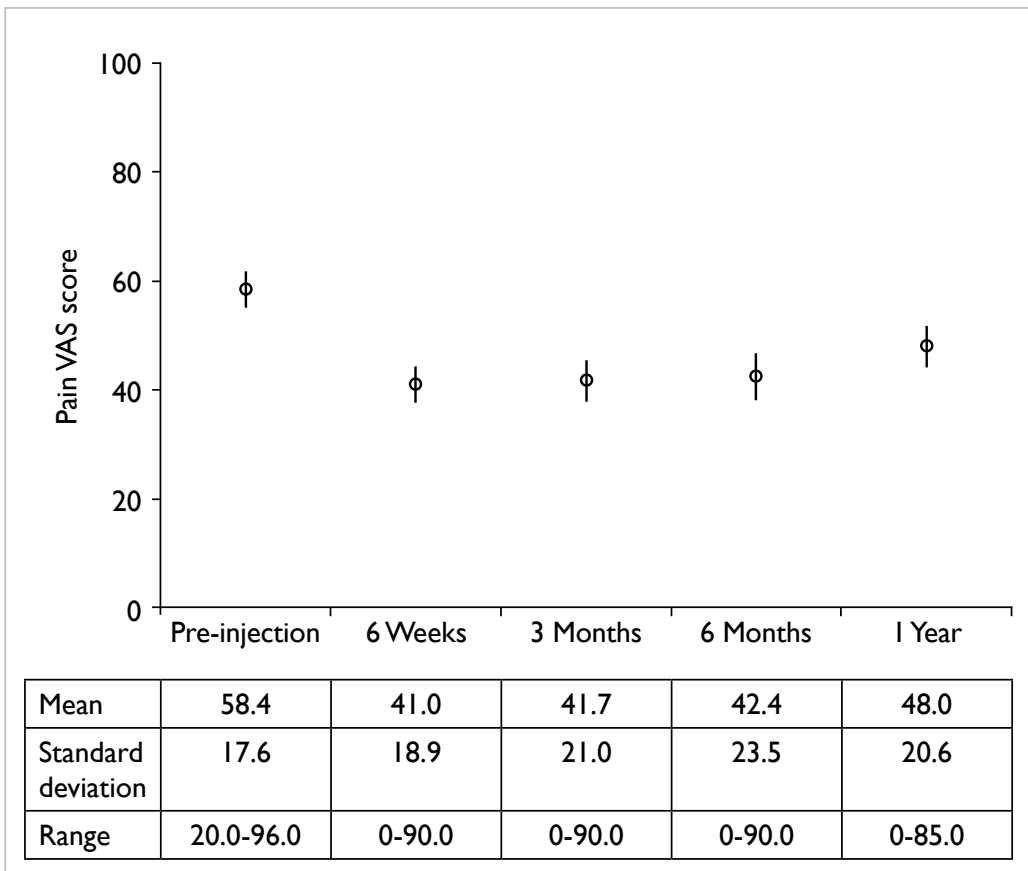

FIG I. Changes in pain visual analogue scale (VAS) scores

The circles represent the means with the vertical lines $95 \%$ confidence intervals. There were significant decreases in VAS scores at 6 weeks, 3 months, 6 months, and I year compared with pre-injection level (all $\mathrm{P}<0.000$ I)

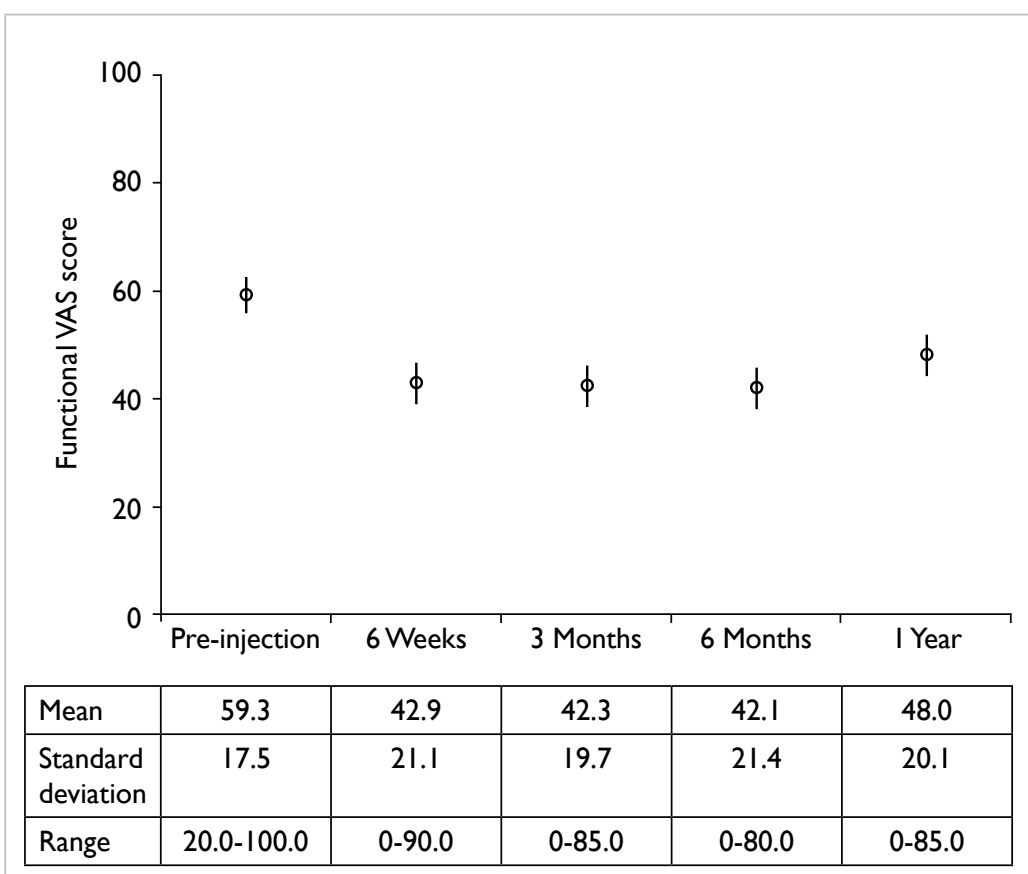

FIG 2. Changes in functional visual analogue scale (VAS) scores

The circles represent the means with the vertical lines $95 \%$ confidence intervals. There were significant decreases in VAS scores at 6 weeks, 3 months, 6 months, and I year compared with pre-injection level (all $\mathrm{P}<0.000 \mathrm{I}$ ) 
Investigation of predictive factors of good clinical response did not demonstrate any significant correlation with age, BMI, pre-injection VAS, ESR, or CRP (Pearson's tests). Sex (Welch's $t$ test) and preinjection KL grade (analysis of variance test) did not significantly affect the treatment response.

Overall, 37 knees had KL grade IV OA, 38 had grade III OA, 30 had grade II OA, and five had grade I OA before injection. Radiographs showed no significant changes in KL OA grades at 3 months and 1 year. A total of 18 (16.4\%) knees experienced adverse events, including pain (14 knees), swelling (2 knees), and warmth (2 knees). All of the adverse events were mild and self-limiting. No patients required hospital admission or extra clinic visits for these self-reported events.

\section{Discussion}

The evidence in the literature is still inconclusive regarding the clinical and biological efficacy of viscosupplementation. The 2006 Cochrane review summarised the results of 76 randomised controlled trials (RCTs) comparing hyaluronic acid (HA) and various other treatment modalities. ${ }^{9}$ The authors concluded that viscosupplementation is an effective treatment for knee OA with beneficial effects on pain, function, and global assessment, especially at the 5- to 13-week post-injection period. Although the sample size restriction may preclude any definitive comment on the safety of the products, no major safety issues were detected. The 2 nd edition of the American Academy of Orthopaedic Surgeons guideline on treatment of knee OA claimed that "we cannot recommend using HA for patients with symptomatic knee OA."10 This recommendation is based on the fact that although meta-analyses of the Western Ontario and McMaster Universities Osteoarthritis Index (WOMAC) for pain, function, and stiffness subscale scores all found statistically significant treatment effects, none of the improvements met the minimum clinically important improvement thresholds. The latest Osteoarthritis Research Society International guideline for nonsurgical management of knee OA claimed that the recommendation for intra-articular $\mathrm{HA}$ injection was 'uncertain', because the inconsistent conclusions among the meta-analyses and conflicting results regarding HA's safety influenced the panel votes. ${ }^{11}$ One of the drawbacks of the meta-analyses and reviews is that they pooled the results of studies that investigated different viscosupplement formulations. These included low- and high-molecular-weight HA preparations of avian or bacterial origin. Hylan G-F 20 is a cross-linked HA derivative of avian origin, with relatively high molecular weight (average, 6000 $\mathrm{kDa}$ ) and fluid rheological properties similar to those of knee synovial fluid of healthy young individuals.
In a 26-week RCT, hylan G-F 20 single-injection formulation resulted in significant improvements in WOMAC pain score, observer-reported disease status, and patient-reported health status score. ${ }^{12}$

Our study is the first in Chinese patients to investigate the efficacy and safety of hylan G-F 20 . The results show that the single 6 - $\mathrm{mL}$ intraarticular injection could significantly improve pain and function in patients with primary knee OA. The beneficial effect could be sustained for up to 6 months. The VAS scores increased again by the 1-year follow-up visit, but the values were still significantly lower than the pre-injection levels. The 5 -point Likert scale also revealed that about $75 \%$ of patients had reduced pain at 3 months, $62 \%$ at 6 months, and the percentage remained decreased at $50 \%$ at the 1-year follow-up visit.

A total of $16.4 \%$ of patients experienced mild and self-limiting local adverse reactions. No pseudoseptic reaction or severe acute inflammatory reaction was reported. ${ }^{13}$ The interview was conducted by telephone at 2 weeks after injection, and was partly carried out by research assistants or nurses. Some patients might have confused 'additional/new pain over the injection site' with 'pre-existing OA pain', which led to the higher self-reported adverse event incidence. There are reports on HA causing adverse reactions; the most common of which is an inflammatory reaction or flare at the injection site characterised by injection site pain and swelling. ${ }^{14-16}$ Hypersensitivity reactions to HA or avian proteins are listed as contra-indications for use of many of the HA products. Many of the inflammatory responses appear to be due to the molecular structure of the HA, as naturally derived hyaluronan sources appear to be better tolerated than highly cross-linked hyaluronan..$^{13,17,18}$ Leopold et $\mathrm{al}^{19}$ demonstrated increased frequency of acute local reaction to hylan G-F 20 in patients receiving more than one course of treatment. Recently a murine model study showed a single injection of hylan G-F 20 led to less inflammation and lower antibody reaction when compared with a three-shot series of injections. In our study, the $6-\mathrm{mL}$ single injection preparation was used. This approach offers another advantage over a multiple-injection regimen as it reduces the number of consultations, therefore saves money and manpower in government hospitals with limited health care resources.

The serial knee radiographs in our study did not show any changes (either progression or regression) of the radiological severity of OA after hylan G-F 20 injection. To date, there is no concrete evidence in the literature to support the disease-modifying effect of HA injection. The radiographic KL grading system may not be sensitive enough to detect minor changes in the articular cartilage. We also did not have a control group for comparison. In a magnetic 
resonance imaging-based $\mathrm{RCT}$ on articular cartilage volume change after four courses of hylan G-F 20 injection at 6-month intervals, the authors claimed that there was less cartilage loss in the treatment group at 24 months $(2.7 \%$ over the medial tibial plateau and $2.6 \%$ over the lateral tibial plateau). ${ }^{20}$ Whether these differences are clinically significant is doubtful, however. We could not find any specific factors predicting good clinical response in our patients. This could be due to the relatively small sample size and the heterogeneity of our patients. The pre-injection parameters we investigated may not be sufficiently sensitive to survive the analysis.

There are a few limitations to this study. The pain and functional VAS scores were used because we believe they are patient-reported outcome measures, which would better reflect the clinical efficacy from the patients' perspectives. The VAS scores are also easy to use, especially in the setting of a multicentre study. We did not include parameters such as knee range of motion, walking tolerance, or other knee scores as they were not the primary objectives of our study. It is well known that the placebo effect may account for $30 \%$ of the perceived benefits of medical treatment. ${ }^{21}$ We could not ascertain how much of the pain relief and functional improvement were attributable to the true therapeutic effects of hylan G-F 20 in view of the nature of our study design. A prospective, blinded, RCT may be able to eliminate the potential confounding factors and information bias. Changes in other treatment modalities during the follow-up period were not compared because of the potential complexity. It is difficult to standardise conservative treatment in terms of oral medication and exercise therapy, simply because patients with advanced knee OA may need stronger analgesics. Patients would also have a high non-compliance rate if we forced them to follow a single regimen. We decided to let all patients carry on with their usual conservative management and asked them if there were any changes in the pain and functional VAS scores during each follow-up after the viscosupplement injection.

\section{Conclusion}

This prospective, multicentre study showed that single intra-articular injection of $6-\mathrm{mL}$ hylan G-F 20 was effective in providing statistically significant pain relief and functional improvement up to 1 year in Chinese patients with primary knee OA. Although adverse events were not uncommon, all of them were mild and self-limiting. Viscosupplementation with hylan G-F 20 could be a safe and beneficial option in managing patients with knee OA.

\section{Declaration}

The authors had not received any forms of financial or non-financial support from commercial companies.
All patients purchased their own injection.

\section{Acknowledgements}

The authors would like to thank Drs Fu-yuen Ng (Queen Mary Hospital), Kan-yip Law (Prince of Wales Hospital), and Paul SC Yip (Queen Elizabeth Hospital) for their contribution of in-patient recruitment and data collection for the study.

\section{References}

1. Felson DT, Naimark A, Anderson J, Kazis L, Castelli W, Meenan RF. The prevalence of knee osteoarthritis in the elderly. The Framingham Osteoarthritis Study. Arthritis Rheum 1987;30:914-8.

2. Zhang $\mathrm{Y}, \mathrm{Xu} \mathrm{L}, \mathrm{Nevitt} \mathrm{MC}$, et al. Comparison of the prevalence of knee osteoarthritis between the elderly Chinese population in Beijing and whites in the United States: The Beijing Osteoarthritis Study. Arthritis Rheum 2001;44:2065-71.

3. Woo J, Leung J, Lau E. Prevalence and correlates of musculoskeletal pain in Chinese elderly and the impact on 4 -year physical function and quality of life. Public Health 2009;123:549-56.

4. Woo J, Lau E, Lau CS, et al. Socioeconomic impact of osteoarthritis in Hong Kong: utilization of health and social services, and direct and indirect costs. Arthritis Rheum 2003;49:526-34.

5. Nelson AE, Allen KD, Golightly YM, Goode AP, Jordan JM. A systematic review of recommendations and guidelines for the management of osteoarthritis: The chronic osteoarthritis management initiative of the U.S. bone and joint initiative. Semin Arthritis Rheum 2013;43:701-12.

6. Mazzucco D, McKinley G, Scott RD, Spector M. Rheology of joint fluid in total knee arthroplasty patients. J Orthop Res 2002;20:1157-63.

7. Fam H, Bryant JT, Kontopoulou M. Rheological properties of synovial fluids. Biorheology 2007;44:59-74.

8. Schurz J, Ribitsch V. Rheology of synovial fluid. Biorheology 1987;24:385-99.

9. Bellamy N, Campbell J, Robinson V, Gee T, Bourne R, Wells G. Viscosupplementation for the treatment of osteoarthritis of the knee. Cochrane Database Syst Rev 2005;(2):CD005321.

10. Jevsevar DS, Brown GA, Jones DL, et al. The American Academy of Orthopaedic Surgeons evidence-based guideline on: treatment of osteoarthritis of the knee, 2nd edition. J Bone Joint Surg Am 2013;95:1885-6.

11. McAlindon TE, Bannuru RR, Sullivan MC, et al. OARSI guidelines for the non-surgical management of knee osteoarthritis. Osteoarthritis Cartilage 2014;22:363-88.

12. Frampton JE. Hylan G-F 20 single-injection formulation. Drugs Aging 2010;27:77-85.

13. Goldberg VM, Coutts RD. Pseudoseptic reactions to hylan viscosupplementation: diagnosis and treatment. Clin Orthop Relat Res 2004;(419):130-7.

14. Lussier A, Cividino AA, McFarlane CA, Olszynski WP, Potashner WJ, De Médicis R. Viscosupplementation with hylan for the treatment of osteoarthritis: findings from clinical practice in Canada. J Rheumatol 1996;23:157985.

15. Hyalgan: prescribing information. Available from: http:// products.sanofi.us/hyalgan/hyalgan.html. Accessed Jan 
2009.

16. Synvisc: information for prescribers. Available from: http:// synviscone.com/ /media/SynviscOneUS/Files/SynviscOnePI-70240104.pdf. Accessed Jan 2010.

17. Reichenbach S, Blank S, Rutjes AW, et al. Hylan versus hyaluronic acid for osteoarthritis of the knee: a systematic review and meta-analysis. Arthritis Rheum 2007;57:1410-8.

18. Jüni P, Reichenbach S, Trelle S, et al. Efficacy and safety of intraarticular hylan or hyaluronic acids for osteoarthritis of the knee: a randomized controlled trial. Arthritis Rheum 2007;56:3610-9.

19. Leopold SS, Warme WJ, Pettis PD, Shott S. Increased frequency of acute local reaction to intra-articular hylan GF-20 (synvisc) in patients receiving more than one course of treatment. J Bone Joint Surg Am 2002;84-A:1619-23.

20. Wang Y, Hall S, Hanna F, et al. Effects of Hylan G-F 20 supplementation on cartilage preservation detected by magnetic resonance imaging in osteoarthritis of the knee: a two-year single-blind clinical trial. BMC Musculoskelet Disord 2011;12:195.

21. Shapiro A, Moris L. The placebo effect in medical and psychological therapies. In: Bergin A, Garfield S, editors. Handbook of psychotherapy and behavior change: an empirical analysis. 2nd ed. New York: Wiley; 1978. 